\title{
Performance Analysis of PI and Fuzzy Control for Modified LCC Resonant Converter Incorporating Boost Converter
}

\author{
N. Madhanakkumar'1, T. S. Sivakumaran² \\ ${ }^{1}$ Department of Electrical and Electronics Engineering, Anna University, Chennai, India \\ ${ }^{2}$ Department of Electrical and Electronics Engineering, Arunai College of Engineering, Tiruvannamalai, India \\ Email: nmadhanakkumar@gmail.com
}

Received 17 March 2016; accepted 14 May 2016; published 17 May 2016

Copyright (C) 2016 by authors and Scientific Research Publishing Inc.

This work is licensed under the Creative Commons Attribution International License (CC BY). http://creativecommons.org/licenses/by/4.0/

(c) (i) Open Access

\begin{abstract}
In this paper, the modified LCC type of series-parallel Resonant Converter (RC) was designed and state-space modeling analysis was implemented. In this proposed converter, one leg of full bridge diode rectifier is replaced with Synchronous Rectifier (SR) switches. The proposed LCC converter is controlled using frequency modulation in the nominal state. During hold-up time, the SR switches control is changed from in-phase to phase-shifted gate signal to obtain high DC voltage conversion ratio. Furthermore, the closed loop PI and fuzzy provide control on the output side without decreasing the switching frequency. The parameter such as conduction loss on primary and secondary side, switching loss, core and copper also reduced. Simultaneously, the efficiency is increased about 94.79 is realized by this scheme. The proposed converter with an input of $40 \mathrm{~V}$ is built to produce an output of $235 \mathrm{~V}$ with the help of ZVS boost converter [1] even under line and load disturbances. As a comparison, the closed loop fuzzy controller performance is feasible and less sensitive than PI controller.
\end{abstract}

\section{Keywords}

LCC Resonant Converter, Synchronous Rectifier (SR), Fuzzy Controller, PI Controller, State-Space Modeling

\section{Introduction}

Today, researches have been made for DC-DC converter to improve the efficiency, power density with reduced switching losses. Due to these increased power semiconductor switching losses, the soft-switching converters 
has been developed. The objective of the proposed converter is to provide remarkable efficiency with regulated responses even under fluctuations in line and load sides by modified LCC Resonant Converter and different control techniques. There are various types of resonant converters [2] [3]. Among these, series-parallel resonant converter (SPRC) is preferred in this work. Both series and parallel resonant converter combines to eliminate the lack of no-load regulation for Series Resonant Converter (SRC), circulating current independent of load for Parallel Resonant Converter (PRC). Many converter topologies and techniques have been proposed. One of the most attractive topology is LCC series-parallel resonant converter is provided. Therefore, the LCC resonant converter is widely used in many applications such as electronic ballast for fluorescent lamps, filament heating, SMPS, particularly in high output voltage and low output current applications [4]-[6]. The general power supply block diagram is shown in Figure 1.

Generally, there are two stages in power supply that has a power factor correction (PFC) stage, a front-end DC-DC converter stage [7] [8]. The purpose of PFC stage is to achieve unity power factor and galvanic isolation, shapes the input current to meet the THD requirement. It provides link input voltage $\mathrm{V}_{\text {link }}$-nom to the DC-DC conversion stage [9] [10]. This front-end converter stage used to regulate the output voltage precisely. Furthermore, to improve the system efficiency after an ac voltage loss certain period of time will maintain the output voltage, called hold-up time. Though there are various techniques for modeling of converter [11] [12], the state-space mathematical modeling is more beneficial than others. The modeling technique is used to analyze the steady state and transient behavior of the resonant tank circuit. The several sections of proposed converter have been discussed here. First the design of proposed converter is to be implemented followed by State Space Mathematical Modeling Analysis and Design of Resonant Tank is to be concentrated. Next section inspected on several Performance Analysis of LCC Resonant Converter followed by Design procedure of PI and Fuzzy Controllers. Finally sections concluded with simulation results and conclusion of proposed work.

\section{Resonant Converter}

\subsection{LCC Resonant Converter}

The LCC resonant converter is now becoming more popular for its easy design and high efficiency, because of zero voltage switching (ZVS) and zero current switching (ZCS) switching conditions. There are many possible combinations of the resonant tank circuit depends upon the inductor and capacitor connections [13]. In this work, LCC resonant tank consist of an inductor (Lr) with series capacitor (Cs) are connected in parallel to the parallel capacitor (Cp). This tank circuit acts as an energy buffer which regulates the energy flow from the input source to output load [14].

In this paper, an SR method is proposed for a new modified LCC resonant converter. It consists of two power MOSFET semiconductor switches for single phase half bridge inverter on the inverter side which gets input from the ZVS boost converter [15] [16]. The transformer secondary side consists of two SR switches 1ø diode bridge rectifier construction. The LCC Resonant Converter Incorporating Boost Converter circuit diagram is shown in Figure 2.

\subsection{Zero Voltage Switching Boost Converter}

The ZVS boost converter is similar to DC-DC boost converter which works under ZVS switching condition thus reduces the switching losses. The capacitive turn-on loss is eliminated by zero voltage switching (ZVS) technique. So, ZVS is more beneficial than ZCS. In this proposed system, the ZVS boost converter is boost up the input voltage of $40 \mathrm{~V}$ to $150 \mathrm{~V}$ which acts as the input to inverter circuit on the primary side of transformer.

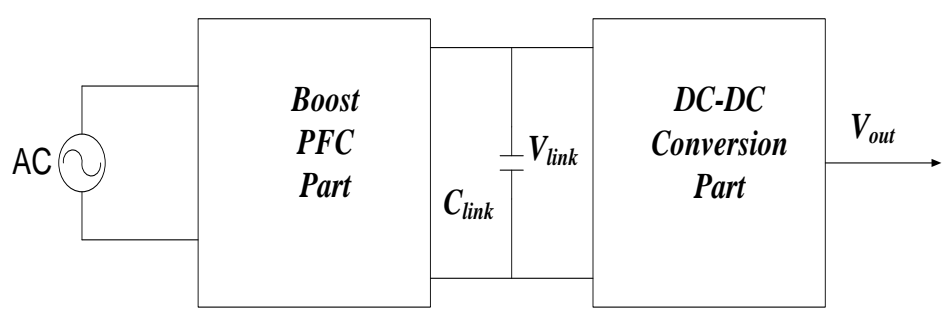

Figure 1. Block diagram of general power supply stages. 


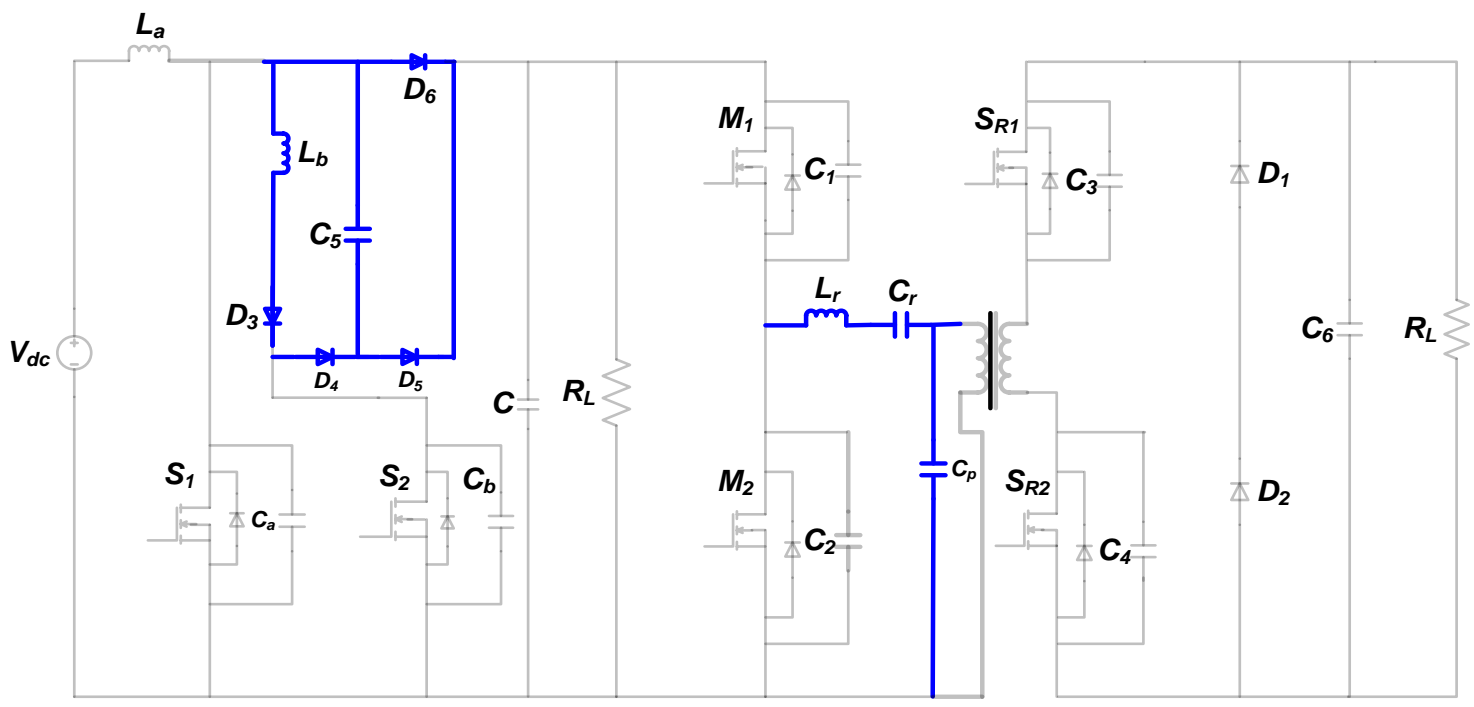

Figure 2. Circuit diagram of LCC resonant converter incorporating boost converter.

The output parameters can be controlled by changing the duty cycle. The ratio of output voltage to input voltage is given in Equation (1).

$$
\frac{V_{O}}{V_{\text {in }}}=\frac{1}{1-D}=\frac{I_{\text {in }}}{I_{O}}
$$

\section{State Space Mathematical Modeling Analysis}

In this paper, the state-space mathematical modeling technique is adopted for LCC resonant converter based on different operating modes [17] [18]. Here, the state equation is applied only for three operating modes.

\subsection{State-Space Analysis}

Some of the following assumptions are made while doing the state-space modeling [19] [20]. The assumptions are:

a) The elements such as switches, inductors, capacitors and diodes used are ideal.

b) The effect of snubber and losses includes tank circuit, semiconductor switches and filter losses are neglected.

c) The filter capacitor $C_{f}$ should be large enough than the parallel capacitor CP to produce constant output voltage $V_{o}$.

d) The high frequency transformer is ideal with turns ratio $n=1$.

e) The input voltage $V_{d c}$ and output voltage $V_{o}$ kept constant without ripples in steady state.

\subsubsection{Mode A}

In mode $\mathrm{A}$, the $\mathrm{M}_{1}$ and $\mathrm{SR}_{2}$ switches are turned on. The tank circuit voltage and resonant current are in-phase. The resonant capacitor Cs boosts inductor current $i_{L}$. So both $i_{L}(t)$ and $V_{C S}(t)$ are positive. The voltage of CP is equal to the output voltage $V_{o}$, because $C_{P}$ is connected in parallel to filter capacitor $C_{f}$. The state-space input and output matrix is given below as Equations (2) and (3).

$$
\left[\begin{array}{c}
\frac{\mathrm{d} i_{L}(t)}{\mathrm{d} t} \\
\frac{\mathrm{d} V_{c s}(t)}{\mathrm{d} t}
\end{array}\right]=\left[\begin{array}{cc}
0 & -\frac{1}{L_{s}} \\
\frac{1}{C_{s}} & 0
\end{array}\right]\left[\begin{array}{c}
i_{L}(t) \\
V_{c s}(t)
\end{array}\right]+\left[\begin{array}{c}
\frac{1}{L_{s}} \\
0
\end{array}\right]\left[V_{d c}-V_{0}\right]
$$

And the output equation is, 


$$
[y]=\left[\begin{array}{ll}
1 & 0 \\
0 & 1
\end{array}\right]\left[\begin{array}{c}
i_{L} \\
V_{c s}
\end{array}\right]
$$

With initial condition $i_{L}(0)$ and $V_{c s}(0)$.

\subsubsection{Mode B}

In this mode of operation, $\mathrm{M}_{2}$ and $\mathrm{SR}_{1}$ pairs are turned on. The power delivered to both tank circuit and load. The $C_{p}$ is connected anti parallel to the filter capacitor. The resonant capacitor $V_{C s}(t)$ and $i_{L}(t)$ are negative. The state-space input and output matrix is given below as Equations (4) and (5).

$$
\left[\begin{array}{c}
\frac{\mathrm{d} i_{L}(t)}{\mathrm{d} t} \\
\frac{\mathrm{d} V_{c s}(t)}{\mathrm{d} t}
\end{array}\right]=\left[\begin{array}{cc}
0 & -\frac{1}{L_{s}} \\
\frac{1}{C_{s}} & 0
\end{array}\right]\left[\begin{array}{c}
i_{L}(t) \\
V_{c s}(t)
\end{array}\right]+\left[\begin{array}{c}
\frac{1}{L_{s}} \\
0
\end{array}\right]\left[V_{d c}+V_{0}\right]
$$

And the output equation is,

$$
[y]=\left[\begin{array}{ll}
1 & 0 \\
0 & 1
\end{array}\right]\left[\begin{array}{c}
i_{L} \\
V_{c s}
\end{array}\right]
$$

With initial condition $i_{L}(0)$ and $V_{c s}(0)$.

\subsubsection{Mode C}

All switches are turned off instead of diode pairs. In this mode, the inductor current and tank circuit voltages are out of phase. So the $i_{L}(t)$ decreases faster. So the energy stored in LCC tank is returned to the source. Here, the resonant current may be positive or negative. The state-space input and output matrix is given below as Equations (6) and (7).

$$
\left[\begin{array}{c}
\frac{\mathrm{d} i_{L}(t)}{\mathrm{d} t} \\
\frac{\mathrm{d} v_{c s}(t)}{\mathrm{d} t} \\
\frac{\mathrm{d} v_{c p}(t)}{\mathrm{d} t}
\end{array}\right]=\left[\begin{array}{ccc}
0 & -\frac{1}{L_{s}} & -\frac{1}{L_{s}} \\
\frac{1}{C_{s}} & 0 & 0 \\
\frac{1}{C_{p}} & 0 & 0
\end{array}\right]\left[\begin{array}{c}
i_{L}(t) \\
V_{c s}(t) \\
V_{c p}(t)
\end{array}\right]+\left[\begin{array}{c}
\frac{1}{L_{s}} \\
0 \\
0
\end{array}\right]\left[V_{d c}\right]
$$

And the output equation is,

$$
[y]=0
$$

\subsection{Stability Analysis}

The Stability analysis refers to the stable working condition of a control system [21] [22]. For a stable system, the output response is predictable, finite and stable for a given input. Thus, system stability is determined from the state-space matrix. The Bode plot for the LCC type of Resonant Converter is shown in Figure 4. The equivalent circuit model of LCC resonant converter is shown in Figure 3.

The transfer function of LCC Resonant Converter is written in Equation (8),

$$
\frac{n V_{0}(S)}{m V(S)}=\frac{C_{s}}{S^{2} C_{s} C_{p} L+C_{s}+C_{p}}
$$

Substituting the values of $L_{s}, C_{s}$ and $C_{P}$, the equation obtained is,

$$
\frac{n V_{0}(S)}{m V(S)}=\frac{470 \times 10^{-9}}{S^{2}\left(0.8978 \times 10^{-18}\right)+1.43 \times 10^{-6}}
$$

The state-space input matrix for the equivalent circuit of LCC converter is written as: 


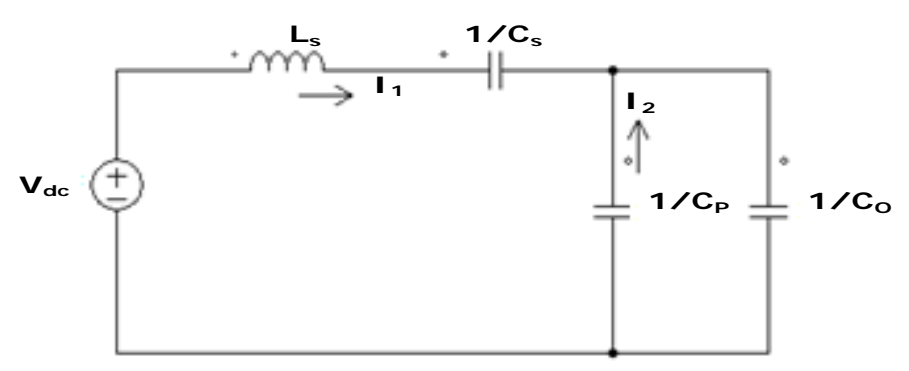

Figure 3. Equivalent circuit model of LCC resonant converter.

$$
\left[\begin{array}{c}
i_{1}^{\prime} \\
i_{2}^{\prime}
\end{array}\right]=\left[\begin{array}{cc}
0 & 1 \\
-\frac{L_{S} C_{S}+L_{S} C_{P}}{L_{S} C_{0} C_{P}} & 0
\end{array}\right]\left[\begin{array}{l}
i_{1} \\
i_{2}
\end{array}\right]+\left[\begin{array}{c}
0 \\
\frac{1}{L_{S} C_{P} C_{0}}
\end{array}\right]\left[V_{d c}\right]
$$

And the output equation is,

$$
[y]=\left[\begin{array}{ll}
0 & L_{S} C_{P} C_{0}
\end{array}\right]\left[\begin{array}{l}
i_{1} \\
i_{2}
\end{array}\right]
$$

The Nyquist Plot for the closed loop control of LCC Resonant Converter is shown in Figure 4. The Plot axes are indicated with the poles and zeros of the LCC Resonant converters. From the plot, the roots are lies on the left half of the s-plane and also the root locus doesn't encircle $-1+\mathrm{j} 0$. So we say that the LCC closed loop control system is stable.

\section{Design of Resonant Tank}

The values are considered for design the LCC resonant tank is $m=C_{s} / C_{\text {Pratio }}=1, Q=5, y=1$. The Load Resistance $R=V_{0} / I_{0}=235 / 2.35=100 \Omega$.

$$
\begin{gathered}
R=\frac{\omega_{0 L}}{Q}=\frac{1}{Q} \sqrt{\frac{L}{C}} \\
\sqrt{\frac{L}{C}}=Q \times R=5 \times 100=500
\end{gathered}
$$

Resonant frequency $f_{0}$ is written as $f_{0}=f / y=127.27 \mathrm{KHz}$. But,

$$
\begin{gathered}
f_{0}=\frac{1}{2 \pi \sqrt{L C}} \\
\frac{1}{\sqrt{L C}}=2 \pi \times 127.27 \times 10^{3}
\end{gathered}
$$

The Value of resonant component $L$ and $C$ are $L_{s}=1.99 \mu \mathrm{H}$ and $C=959.6 \mathrm{Nf}$.

\section{Performance Analysis of LCC Converter}

\subsection{Loss Analysis}

The transformer of high frequency causes loss on both primary and secondary side. The secondary side is calculated by summing the loss of diode rectifier and SR switches. The transformer size will be reduced because of its high frequency. There is various loss parameters such as conduction loss, core loss, copper loss, switching loss can be calculated as following equations.

$$
P_{\text {cond }}=I_{\text {on }}^{2} R_{d s}
$$

where, $I_{o n}$ is the drain current of the power MOSFET switch, $R_{d s}$ is the drain to source resistance of the switch. 


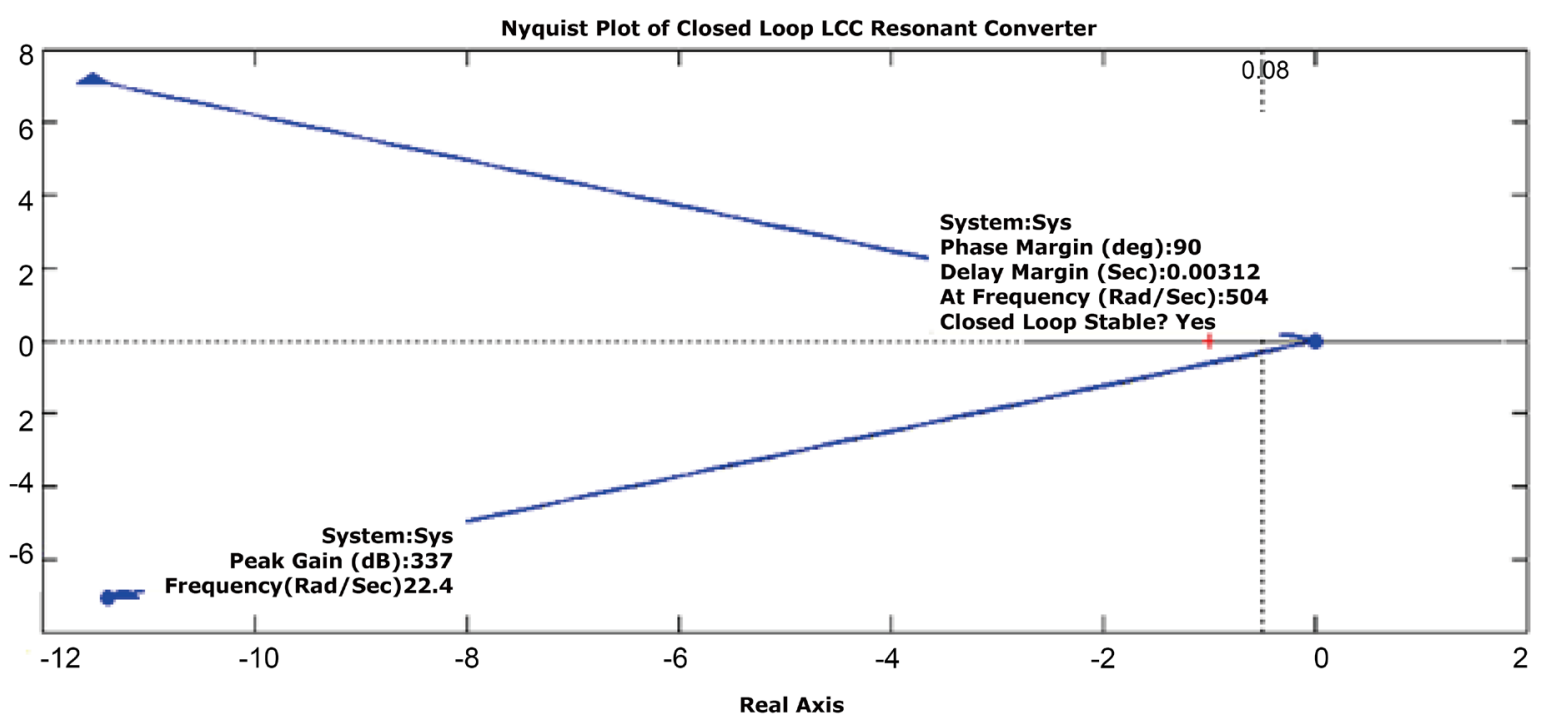

Figure 4. Stability analysis of closed loop LCC resonant converter using Nyquist Plot.

But, the loss occur at SR switch is very less than diode rectifier.

The Switching loss is calculated as follows,

$$
P_{s w}=\left(C_{o}+C_{P}\right) V^{2} f_{s w}
$$

where, $C_{o}$ is the output capacitance of the MOSFET, $C_{P}$ is the Parasitic winding capacitance of the MOSFET switch. $f_{s w}$ is the switching frequency of the Resonant Converter. The total losses are calculated by the sum of conduction loss and switching loss. Figure 5 shows Circuit Simulator employing for loss calculation, where $u_{s}$ is blocking voltage. When switch becomes turned $\mathrm{ON}$, the value of $u_{s}$ is zero. $I_{S}$ is switching current and $T_{J}$ is junction temperature of the switch [23]. From Loss Calculation Box which was implemented in MATLAB shown that $P_{\text {cond }}=20.2 \mathrm{~W}$ and $P_{s w}=10.3 \mathrm{~W}$. The loss chart for the LCC Resonant converter is shown in Figure 6 .

$$
P_{\text {total }}=P_{\text {cond }}+P_{\text {sw }}=30.3 \mathrm{~W}
$$

\subsection{Voltage Conversion Ratio}

The proposed LCC Resonant converter has different voltage conversion ratios depend on its operation. In the nominal state, the LCC converter operates near Resonant Frequency $f_{r}$ to attain optimum efficiency. The Voltage Conversion Ratio and operating frequency also of the LCC Resonant Converter is analyzed and the corresponding graph can be obtained by using the equation given below.

$$
\frac{V_{\text {out }}}{V_{\text {in }}}=\frac{1}{\sqrt{\frac{\pi^{2}}{8}}\left[1+K\left(1-\omega^{2}\right)\right]^{2}+\left[Q_{r}\left(\omega-\frac{1}{\omega}\right)\right]^{2}}
$$

where $V_{0}$ is the output Voltage, $V_{\text {in }}$ is the input Voltage, Gain $K=C_{P} / C_{S}$ ratio which is equal to 1 . The Resonant frequency and Quality factor of LCC Resonant Converter are given as,

$$
Q=\frac{Z_{L}}{\sqrt{\frac{L}{\frac{C_{s} C_{p}}{C_{s}+C_{p}}}}} \text { and } f_{0}=\frac{1}{2 \pi \sqrt{L \frac{C_{s} C_{p}}{C_{s+} C_{p}}}}
$$

The load impedance $Z_{L}=V_{\min } / I_{L \min }=132 / 2.2=60 \Omega$. The angular frequency is written as $\omega=\omega_{s} / \omega_{r}$. Where $\omega_{s}=2 \pi f_{s}$ is the angular switching frequency of LCC converter. $\omega_{r}=2 \pi f_{r}$ is the angular resonant frequency [24]. 


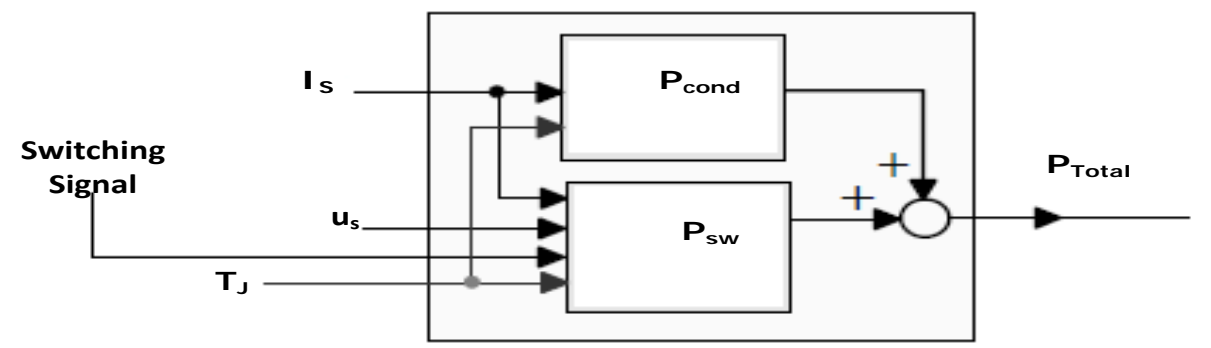

Figure 5. Circuit simulator employing loss calculation.

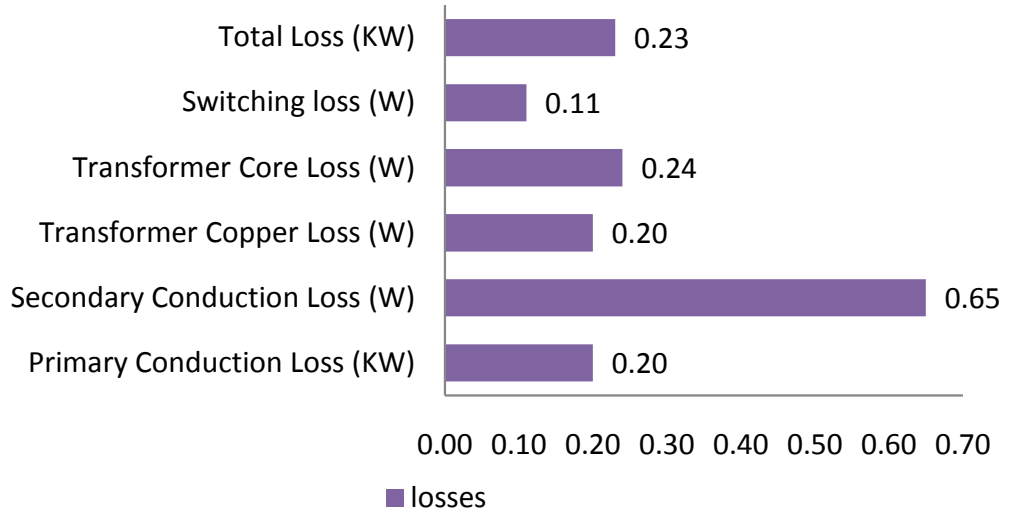

Figure 6. Loss chart for the LCC Resonant converter.

\subsection{Efficiency}

Efficiency calculation is done for different loading conditions. Figure 7 shows the efficiency in percentage for variation in loads. The chart could evident that even at full loading condition, the proposed converter able to sustain at $94.79 \%$ of efficiency.

$$
\begin{gathered}
\operatorname{Efficiency}(\eta)=\frac{\text { Output Power }\left(P_{\text {OUT }}\right)}{\text { Output Power }\left(P_{\text {OUT }}\right)+\operatorname{Total} \operatorname{Losses}\left(P_{T}\right)} \\
\text { Efficiency }=V_{o} I_{o} /\left(V_{o} \cdot I_{o}+P_{\text {total }}\right) \\
\eta=\frac{552.25}{552.25+30.3} \times 100=94.79 \%
\end{gathered}
$$

\section{Design of PI Controller}

The closed loop PI controller is provided on the output side to provide controlled gate signal to switches under different load conditions. Both proportional and integral term is to increase the speed of the response and also to eliminate steady state error. The controller gains $\mathrm{K}_{\mathrm{P}}$ and $\mathrm{K}_{\mathrm{I}}$ are tuned by trial and error according to the system error signal. Figure 8 shows the block diagram representation of PI control based LCC resonant converter.

\section{Design of Closed Loop Fuzzy Control}

The fuzzy controller is a problem solving control system that operates in a closed-loop system in real time. The limitations of conventional (PI) controller are overcome by fuzzy controller. The fuzzy controller is beneficial because it is very robust, cheap, and simple to design and has the multiple inputs and multiple outputs. Figure 9 shows the block diagram representation of fuzzy control based LCC resonant converter.

Fuzzy logic system is an artificial decision maker based that operates on combinations of Linguistic variable and Boolean logic. Usually fuzzy logic control structure is created from four major elements presented on Figure 10. 


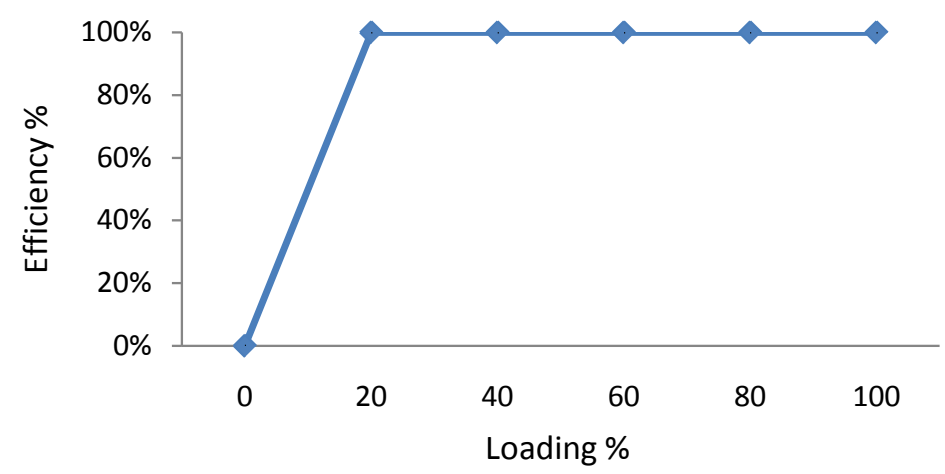

Figure 7. Plot for efficiency versus different values of loading in \%.

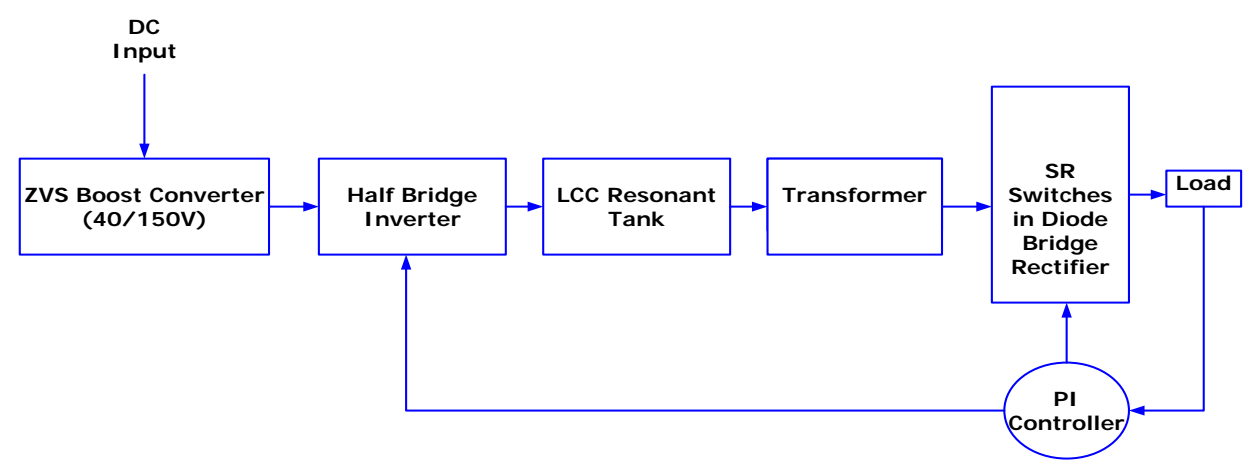

Figure 8. Block diagram of PI control based LCC resonant converter.

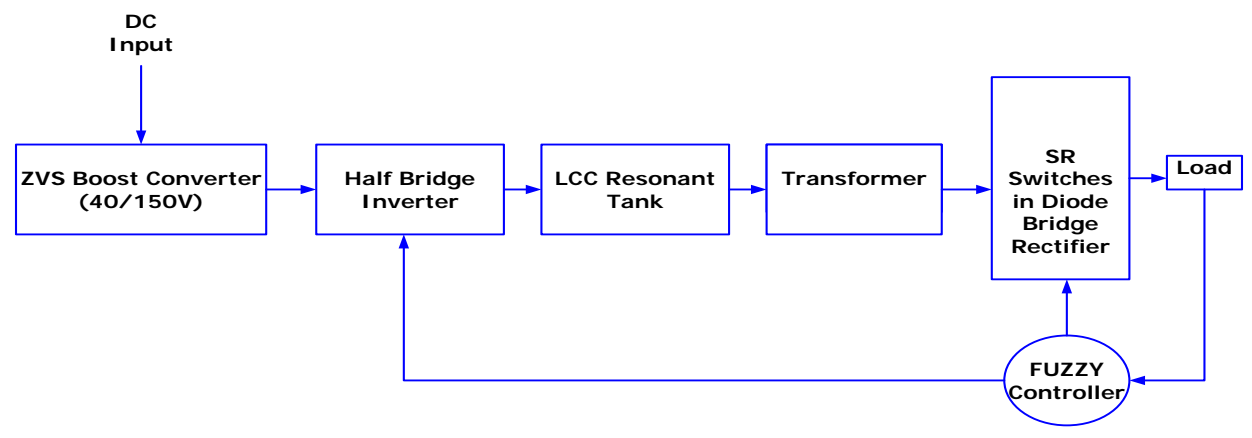

Figure 9. Block diagram of fuzzy control based LCC Resonant converter.

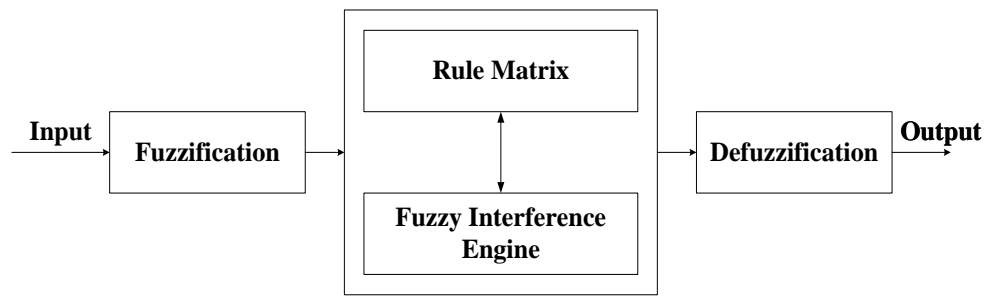

Figure 10. Structure of fuzzy controller.

\subsection{Fuzzification}

This first phase of fuzzy logic is to deliver the crisp input variables for given fuzzy with the help of membership functions. The inference mechanism formulating the mapping for given input to output. It is done by using mamdani or sugeno type toolbox. 


\subsection{Rules and Database}

It consist of a database and linguistic control rules are framed by if-then conditional statement with AND/OR logic operation. The fuzzy rules based on the error $\mathrm{E}$, the rate of change of error $\Delta \mathrm{E}$ and the change in the control signal is the output obtained. Here, 49 rules are used to form rule base table.

\subsection{Variable Frequency in Phase Disposition Pulse Width Modulation System}

Defuzzification phase converts the fuzzy output from the crisp output. The crisp output is the pulse signal generated to the power switches on the SR switches and half bridge inverter. There are many methods of defuzzification that have been proposed. The center of gravity is physically appealing among those methods. It is found by calculating the area bounded by the membership function curve. The general structure of fuzzy controller in block diagram representation is shown in Figure 10.

In this proposed work, the seven triangular membership functions are used. The fuzzy rule base table is shown in Table 1 based on trial and error method.

\section{Simulation Results}

The simulation results shows the responses of closed loop PI and Fuzzy controller of LCC Resonant Converter with set point of $40 \mathrm{~V}$ for nominal load of $100 \Omega$. The Figure 11 and Figure 12 shows respective PI controller responses of output voltage and current under sudden line disturbances $(40 \mathrm{~V}-50 \mathrm{~V}-40 \mathrm{~V})$ at $0.5 \mathrm{sec}$ with nominal load of $100 \Omega$ and Figure 13 and Figure 14 shows respective PI controller responses of output voltage

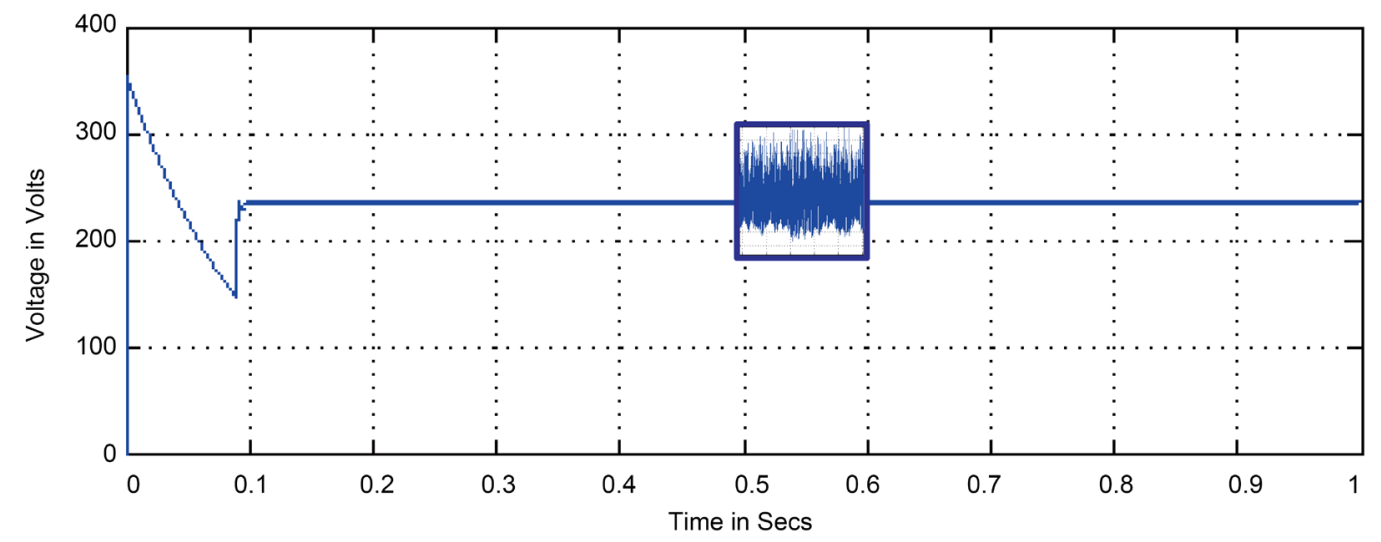

Figure 11. Simulated output voltage of LCC RC with sudden line disturbances (40 V - $50 \mathrm{~V}-40 \mathrm{~V})$ at $\mathrm{t}=0.5 \mathrm{sec}(\mathrm{PI}$ Controller).

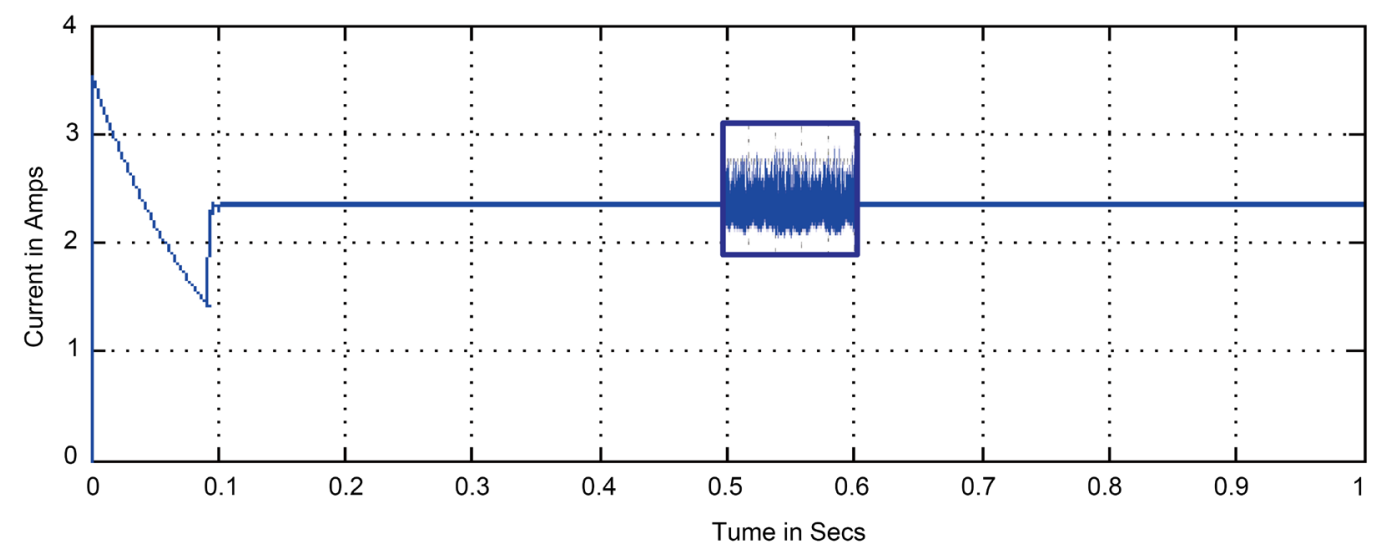

Figure 12. Simulated output current of LCC RC with sudden line disturbances $(40 \mathrm{~V}-50 \mathrm{~V}-40 \mathrm{~V})$ at $\mathrm{t}=0.5 \mathrm{sec}(\mathrm{PI}$ Controller). 


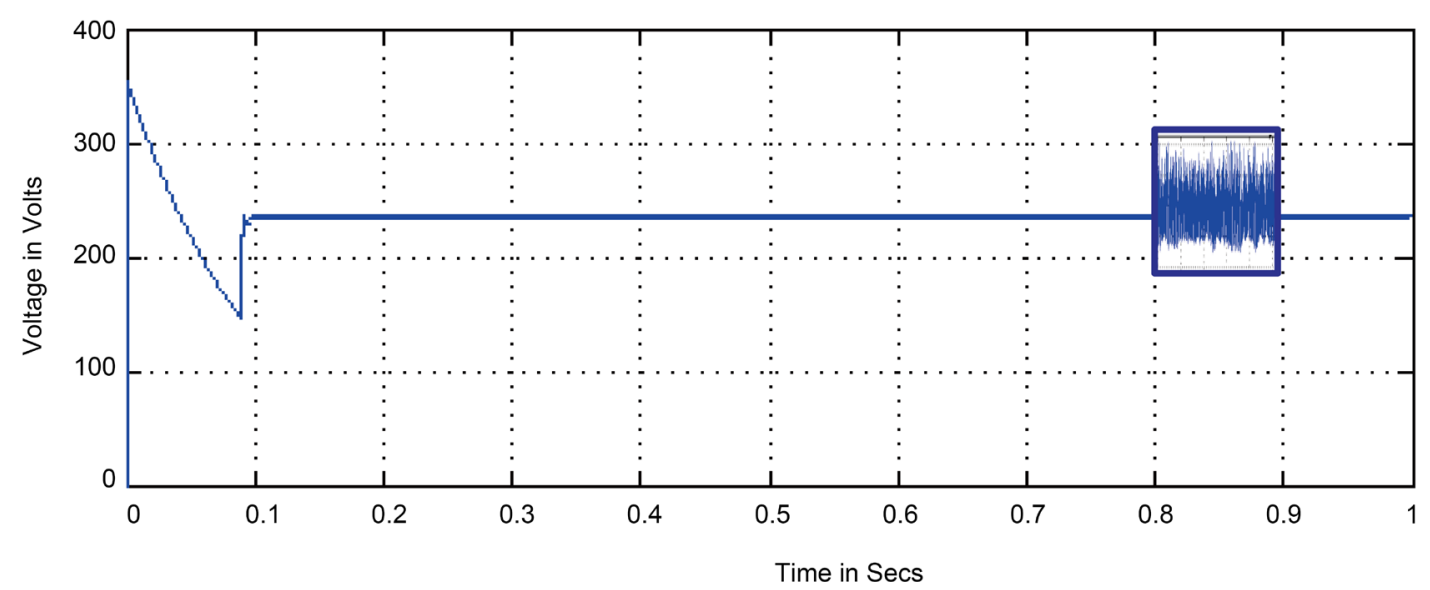

Figure 13. Simulated output voltage of LCC RC with sudden load disturbances $(100 \Omega-90 \Omega-100 \Omega$ ) at $t=0.8$ sec (PI Controller).

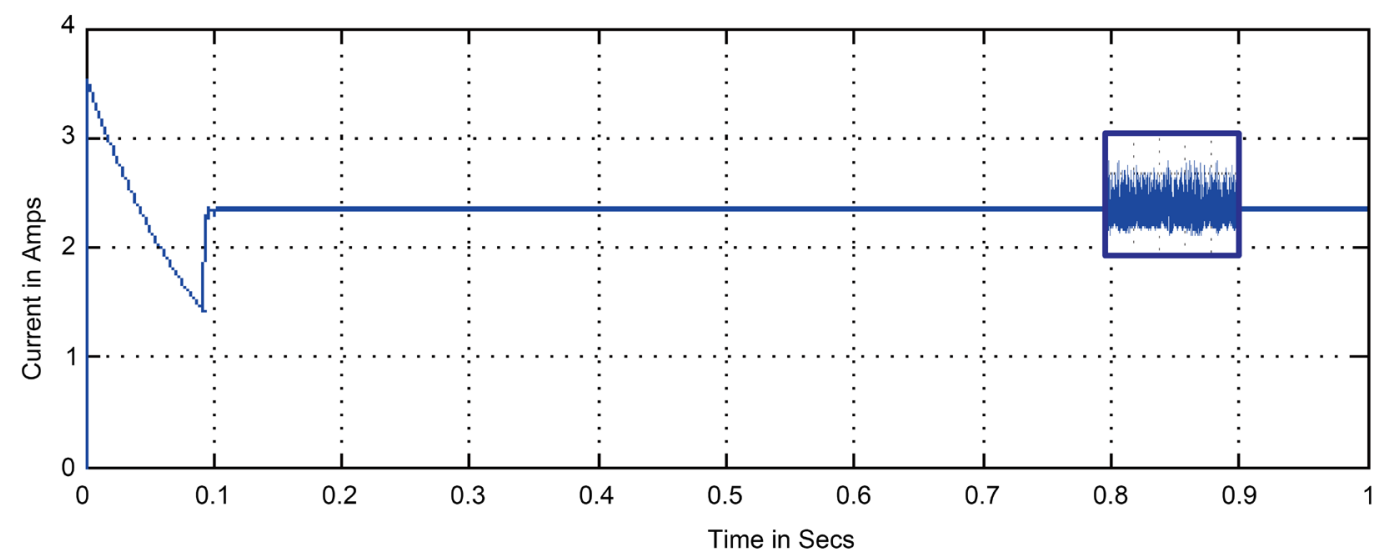

Figure 14. Simulated output current of LCC RC with sudden load disturbances $(100 \Omega-90 \Omega-100 \Omega)$ at $t=0.8$ sec (PI Controller).

Table 1. Fuzzy rule base.

\begin{tabular}{|c|c|c|c|c|c|c|c|}
\hline 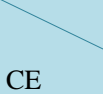 & NB & NM & NS & Z & PB & $\mathrm{PM}$ & PS \\
\hline NB & NB & NB & NM & NM & NS & NS & $\mathrm{Z}$ \\
\hline NM & NB & NM & NM & NS & NS & Z & PB \\
\hline NS & NM & NM & NS & NS & $\mathrm{Z}$ & PB & PB \\
\hline Z & NM & NS & NS & Z & PB & PB & $\mathrm{PM}$ \\
\hline PB & NS & NS & Z & PB & PB & PM & PM \\
\hline PM & NS & Z & PB & PB & PM & PM & PS \\
\hline PS & Z & PB & PB & PM & PM & PS & PS \\
\hline
\end{tabular}

and current under sudden load disturbance (100 $\Omega$ - $90 \Omega$ - $100 \Omega)$ at $0.8 \mathrm{sec}$. The Figure 15 and Figure 16 shows respective Fuzzy controller responses of output voltage and current under sudden line disturbances (40 V - $50 \mathrm{~V}$ - $40 \mathrm{~V}$ ) at $0.5 \mathrm{sec}$ with nominal load of $100 \Omega$ and Figure 17 and Figure 18 shows respective Fuzzy controller responses of output voltage and current under sudden load disturbance $(100 \Omega-90 \Omega-100 \Omega)$ at 0.8 sec. Similarly, the performance evaluation of conventional PI controller is compared with closed loop fuzzy controller under various disturbances are shown in Table 2. The Table 3 shows parameter specifications of LCC resonant converter. Figure 19 shows the comparison graph of PI and Fuzzy controller for LCC Resonant converter. From 


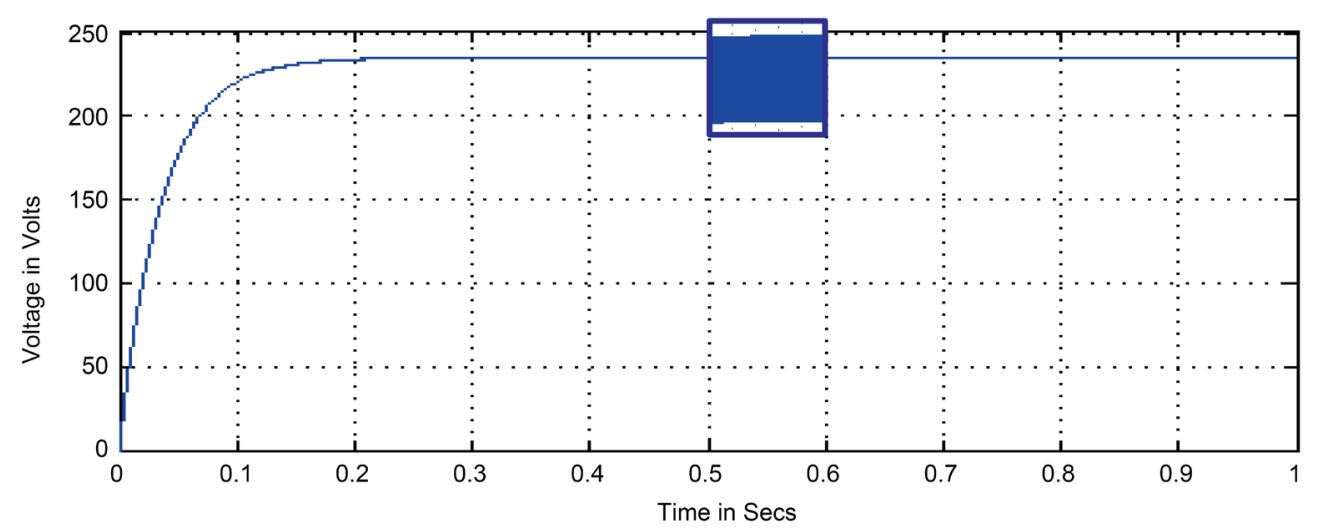

Figure 15. Simulated output voltage of LCC RC with sudden line disturbances $(40 \mathrm{~V}-50 \mathrm{~V}-40 \mathrm{~V})$ at $\mathrm{t}=0.5 \mathrm{sec}($ Fuzzy Controller).

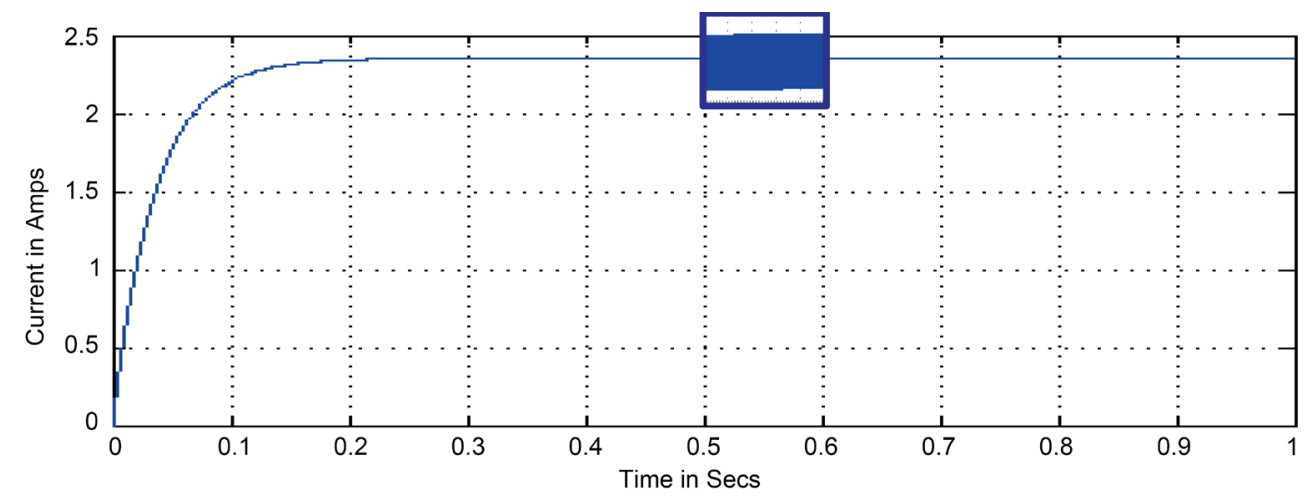

Figure 16. Simulated output current of LCC RC with sudden line disturbances $(40 \mathrm{~V}-50 \mathrm{~V}-40 \mathrm{~V})$ at $\mathrm{t}=0.5$ sec $($ Fuzzy Controller).

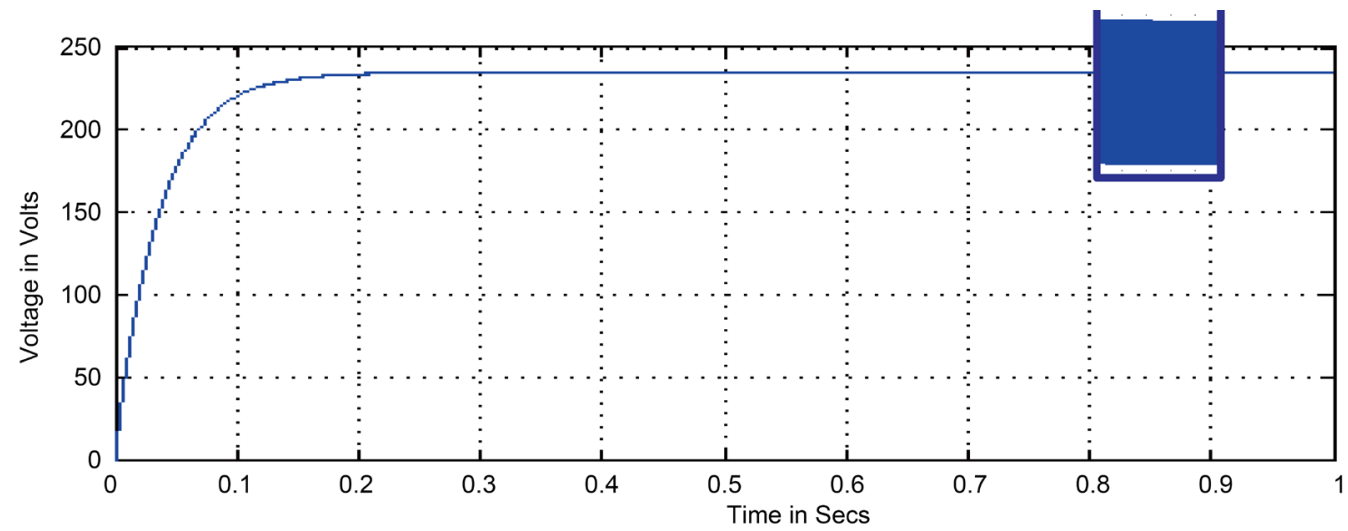

Figure 17. Simulated output voltage of LCC RC with sudden load disturbances $(100 \Omega-90 \Omega-100 \Omega)$ at $t=0.8$ sec (Fuzzy Controller).

Table 2. Performance evaluation of closed loop fuzzy control with PI control Of LCC resonant converter.

\begin{tabular}{cccc}
\hline \multirow{2}{*}{$\begin{array}{c}\text { LCC Resonant } \\
\text { Converter }\end{array}$} & \multicolumn{3}{c}{$\begin{array}{c}\text { Supply Voltage Increase by 10 V (Line disturbance) \& } \\
\text { Load Resistance decrease by } 10 \Omega \text { (Load disturbance) }\end{array}$} \\
\cline { 2 - 4 } FUZZY & Delay time (msec) & Rise Time (msec) & Settling time (msec) \\
PI & 20.1 & 70.1 & 60.2 \\
\hline
\end{tabular}




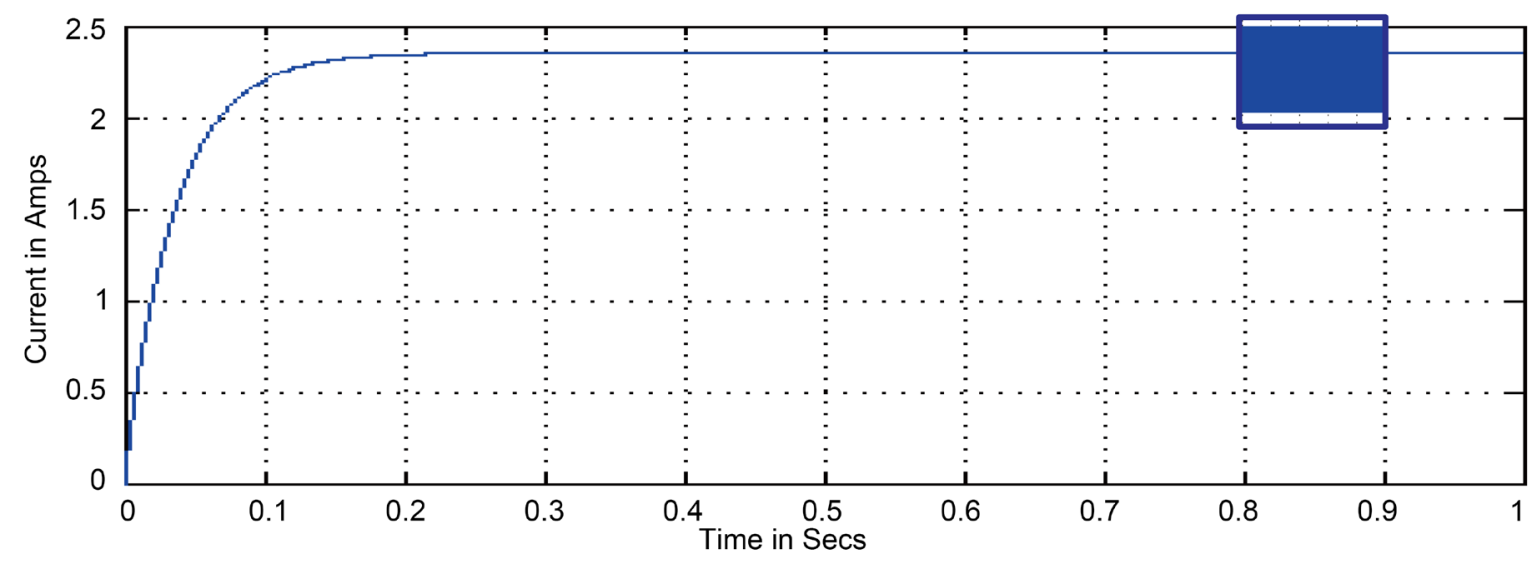

Figure 18. Simulated output current of LCC RC with sudden load disturbances $(100 \Omega-90 \Omega-100 \Omega)$ at $\mathrm{t}=0.8 \mathrm{sec}($ Fuzzy Controller).

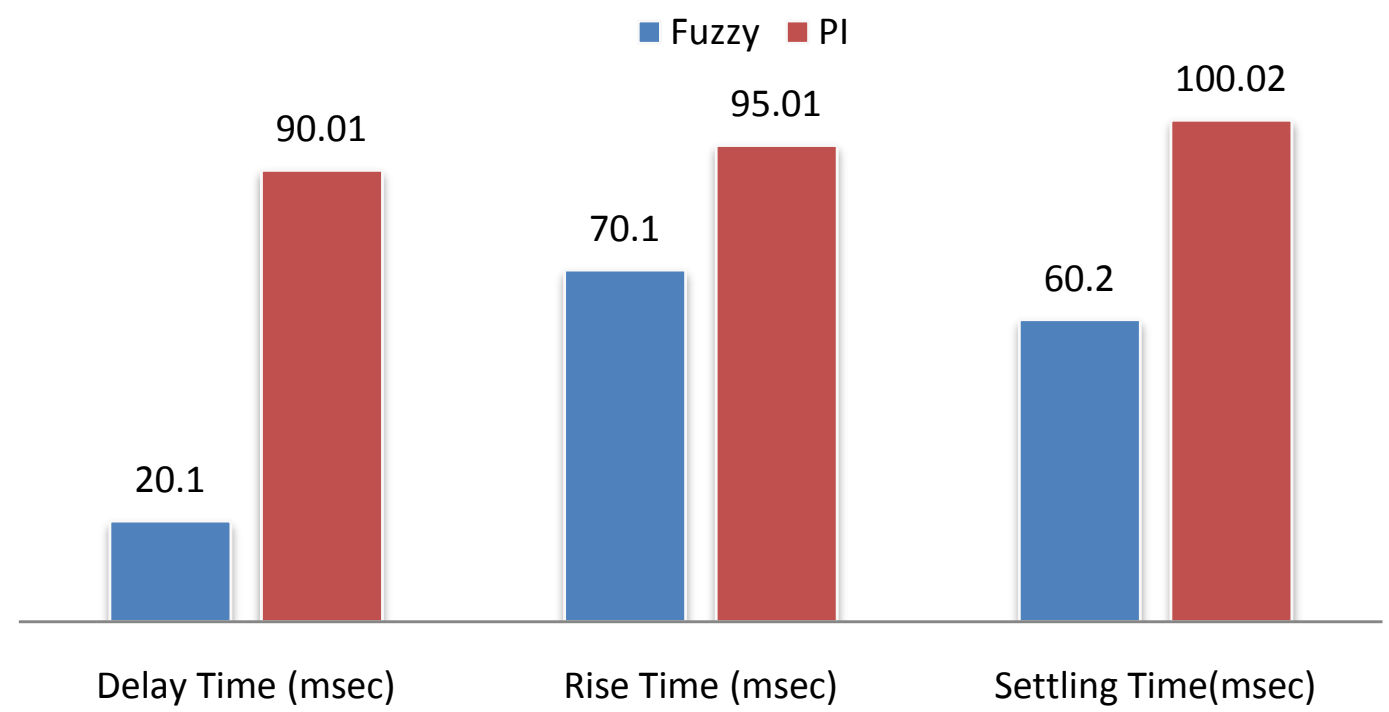

Figure 19. Graphical comparison of simulated performances of closed loop fuzzy control and PI control for LCC RC from Table 2.

Table 3. Parameters specification for LCC resonant converter.

\begin{tabular}{cc}
\hline PARAMETERS & VALUES \\
\hline Input Voltage, $\mathrm{V}_{\mathrm{dc}}$ & $40 \mathrm{~V}$ \\
Resonant Inductor, $\mathrm{L}_{\mathrm{r}}$ & $1.99 \mu \mathrm{H}$ \\
Resonant Series Capacitor, $\mathrm{C}_{\mathrm{S}}$ & $470 \mathrm{nF}$ \\
Resonant Parallel Capacitor, $\mathrm{C}_{\mathrm{p}}$ & $960 \mathrm{nF}$ \\
Load Resistance, $\mathrm{R}_{\mathrm{L}}$ & $100 \Omega$ \\
Output Voltage, $\mathrm{V}_{\mathrm{o}}$ & $235 \mathrm{~V}$ \\
Output Current, $\mathrm{I}_{\mathrm{o}}$ & $2.35 \mathrm{~A}$ \\
\hline
\end{tabular}

the results of PI and Fuzzy controlled converter, we could evident that Fuzzy controlled converter had less distraction under sudden load and line disturbances. 


\section{Conclusion}

In this paper, the modified LCC type of Series-Parallel Resonant Converter was proposed. During hold-up time, the SR switches operate with phase-shifted gate signal to obtain high voltage conversion ratio without reduction in switching frequency. Thus, the closed loop control of LCC resonant converter performance was obtained using fuzzy and PI controller. The simulation results show that the fuzzy controller yields better dynamic performance even under sudden load and line disturbances. The stability of the system was also analyzed with the help of Nyquist plot. Furthermore, state-space analysis modeling technique is adapted. Likewise, the reduction of loss will lead to attain $94.79 \%$ of efficiency. From the simulation results, it is found that the closed loop fuzzy control system is less susceptible to the disturbances than PI.

\section{References}

[1] Madhanakkumar, N., Sivakumaran, T.S., Irusapparajan, G. and Sujitha, D. (2014) Closed Loop Control of LLC Resonant Converter Incorporating ZVS Boost Converter. International Journal of Engineering and Technology, 6.

[2] Fang, X., Hu, H.B., Chen, F., Somani, U., Auadisian, E., Shen, J. and Batarseh, I. (2013) Efficiency-Oriented Optimal Design of the LLC Resonant Converter Based on Peak Gain Placement. IEEE Transactions on Power Electronics, 28.

[3] Oeder, C. (2010) Analysis and Design of a Low-Profile LLC Converter. IEEE International Symposium on Industrial Electronics, 3859-3864. http://dx.doi.org/10.1109/isie.2010.5637747

[4] Xie, X., Zhang, J., Zhao, C., Zhao, Z. and Qian, Z. (2007) Analysis and Optimization of LLC Resonant Converter with a Novel Over-Current Protection Circuit. IEEE Transactions on Power Electronics, 22, 435-443. http://dx.doi.org/10.1109/TPEL.2006.889919

[5] Foster, M.P., Gould, C.R., Gilbert, A.J., Stone, D.A. and Bingham, C.M. (2008) Analysis of CLL Voltage-Output Resonant Converters Using Describing Functions. IEEE Transactions on Power Electronics, 23, 1772-1781. http://dx.doi.org/10.1109/TPEL.2008.924835

[6] Duerbaum, T. (1998) First Harmonic Approximation including Design Constraints. Twentieth International Telecommunications Energy Conference Proceedings, 321-328.

[7] Choi, W.-Y., Kwon, J.-M. and Kwon, B.-H. (2006) High-Performance Front-End Rectifier System for Telecommunication Power Supplies. IEE Proceedings-Electric Power Applications, 153, 473-482. http://dx.doi.org/10.1049/ip-epa:20050257

[8] de Groot, H., Janssen, E., Pagano, R. and Schetters, K. (2007) Design of a 1-MHz LLC Resonant Converter Based on a DSP-Driven SOI Half-Bridge Power MOS Module. IEEE Transactions on Power Electronics, 22, 2307-2320. http://dx.doi.org/10.1109/TPEL.2007.904203

[9] Yang, B., Lee, F.C., Zhang, A.J. and Huang, G. (2002) LLC Resonant Converter for Front End DC-DC Conversion. Seventeenth Annual IEEE Applied Power Electronics Conference and Exposition, 1108-1112.

[10] Cheng, J.H. and Witulski, A.F. (1998) Analytic Solutions for LLCC Parallel Resonant Converter Simplify Use of Twoand Three-Element Converters. IEEE Transactions on Power Electronics, 13, 235-243. http://dx.doi.org/10.1109/63.662828

[11] Lee, B., Kim, M., Kim, C., Park, K. and Moon, G. (2009) Analysis of LLC resonant Converter Considering Effects of Parasitic Components. International Telecommunications Energy Conference, 1-6. http://dx.doi.org/10.1109/intlec.2009.5351740

[12] Ivensky, G., Bronshtein, S. and Abramovitz, A. (2011) Approximate Analysis of Resonant LLC DC-DC Converter. IEEE Transactions on Power Electronics, 26, 3274-3284. http://dx.doi.org/10.1109/TPEL.2011.2142009

[13] Lin, B.-R. and Du, Y.-K. (2015) Medium Voltage Resonant Converter with Balanced Input Capacitor Voltages and Output Diode Currents. Journal of Power Electronics, 15, 389-398. http://dx.doi.org/10.6113/JPE.2015.15.2.389

[14] Beiranvand, R., Rashidian, B., Zolghadri, M.R. and Alavi, S.M.H. (2010) Designing an Adjustable Wide Range Regulated Current Source. IEEE Transactions on Power Electronics, 25, 197-208. http://dx.doi.org/10.1109/TPEL.2009.2027237

[15] Steigerwald, R.L. (1988) A Comparison of Half-Bridge Resonant Converter Topologies. IEEE Transactions on Power Electronics, 3, 174-182. http://dx.doi.org/10.1109/63.4347

[16] Liu, T., Zhou, Z., Xiong, A., Zeng, J. and Ying, J. (2006) A Novel Precise Design Method for LLC Series Resonant Converter. Twenty-Eighth International Telecommunications Energy Conference, 1-6. http://dx.doi.org/10.1109/intlec.2006.251606

[17] Fang, X., Hu, H., Shen, J. and Batarseh, I. (2012) Operation Mode Analysis and Peak Gain Approximation of the LLC Resonant Converter. IEEE Transactions on Power Electronics, 27, 1985-1995. 
http://dx.doi.org/10.1109/TPEL.2011.2168545

[18] Lu, B., Liu, W., Liang, Y., Lee, F.C. and van Wyk, J.D. (2006) Optimal Design Methodology for LLC Resonant Converter. Twenty-First Annual IEEE Applied Power Electronics Conference and Exposition, 2, 6.

[19] Batarseh, I. (1995) State-Plane Approach for the Analysis of Half-Bridge Parallel Resonant Converters. IEE Proceedings_Circuits, Devices and Systems, 142, 200-204. http://dx.doi.org/10.1049/ip-cds:19951890

[20] Bhat, A.K.S. (1998) A Generalized Steady-State Analysis of Resonant Converters Using Two-Port Model and Fourier-Series Approach. IEEE Transactions on Power Electronics, 13, 142-151. http://dx.doi.org/10.1109/63.654968

[21] Batarseh, I., Liu, R., Ortiz-Conde, A., Yacoub, A. and Siri, K. (1994) Steady State Analysis and Performance Characteristics of the LLC-Type Parallel Resonant Converter. Power Electronics Specialists Conference, 597-606. http://dx.doi.org/10.1109/pesc.1994.349675

[22] Lazar, J.F. and Martinelli, R. (2001) Steady-State Analysis of the LLC Series Resonant Converter. Sixteenth Annual IEEE Applied Power Electronics Conference and Exposition, 2, 728-735. http://dx.doi.org/10.1109/apec.2001.912451

[23] Drofenik, U. and Kolar, J.W. A General Scheme for Calculating Switching- and Conduction-Losses of Power Semiconductors in Numerical Circuit Simulations of Power Electronic Systems. Power Electronic Systems Laboratory (PES), ETH Zurich ETH-Zentrum, Zurich. www.pes.ee.ethz.ch

[24] Kutkut, N.H., Lee, C.Q. and Batarseh, I. (1998) A Generalized Program for Extracting the Control Characteristics of Resonant Converters via the State-Plane Diagram. IEEE Transactions on Power Electronics, 13, 58-66. http://dx.doi.org/10.1109/63.654959 